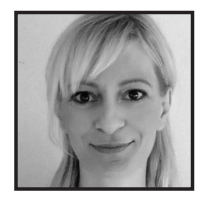

\title{
Transition From Primary to Secondary School Through Visual Arts Education
}

\author{
Martha Christopoulou, Greek Ministry of Education, Research \& \\ Religious Affairs
}

\begin{abstract}
Moving from primary to secondary school is a major challenge. This article presents the concept of educational transition, makes a case for its relationship with identity formation, and discusses its effects on students' academic achievement, social adjustment, and self-concepts. It explores the role of art and creativity to foster resilience and presents an example of how visual arts were used to help students negotiate and reframe transition. It concludes with further practical considerations for art education with the hope that visual arts can play a critical role in ensuring that students successfully meet the challenges along the way to secondary school.
\end{abstract}

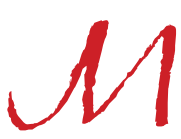

oving from primary to secondary school is seen as a significant event in every child's life and a major challenge in early adolescence. Students may find it exciting and/or scary and feel anticipatory anxiety and satisfaction to be moving from a small familiar environment to a larger, more heterogeneous school and going from being the oldest group in the school to the youngest. A range of practices have been employed by schools in order to ease transition and adjustment to the new environment. These include dissemination of information about the new school, use of "bridging" material, prior visits by students, teachers, and/or parents, distribution of booklets, talks at schools, orientation on arrival, peer support programs, and joint social events between schools (Hanewald, 2013; Evangelou et al., 2008). 
However, a literature review and web search provided few examples of how the visual arts can be incorporated in school programs to address transition. Considering that the visual arts have the potential to enable students to explore and examine themes and issues relevant to transition, I conducted an artful inquiry with sixth-graders at a public primary school in Athens, Greece. After presenting the concept of educational transition and its relationship to identity formation and resilience, this article reports on the inquiry. Moreover, it discusses further practical considerations for art education with the hope that visual arts can play a critical role in ensuring that students successfully meet the challenges along the way to secondary school.

\section{Defining Educational Transition}

In educational terms, transition refers to the process of moving from one setting or activity to another and is associated with a move from one phase of education to another (Anderson, Jacobs, Schramm, \& Splittgerber, 2000). During transition periods, students have to cope with and adapt to a number of changes relating to school structure, culture and ethos, social interactions, classroom organization, contexts of learning, teaching style, academic work standards, student diversity, curriculum discontinuity, and new forms of school discipline (Fabian \& Dunlop, 2005).

Educational transitions bring with them the excitement of new beginnings, the satisfaction of successful completion of a learning cycle, and the opportunity of learning new things. They also bring with them the anticipation of meeting new teachers and classmates and making new friends as well as concerns of social acceptance and fear of losing old friends. Transition, therefore, can be understood not only as a period of change, but also as the experience of changing (Gorgorió, Planas, \& Vilella, 2002). The ways students experience transitions are affected by their biological, psychosocial, cognitive, and emotional development and social factors such as family, school, and community.

\section{Transition as an Ecological Concept}

According to Bronfenbrenner's (1979) ecological theory, children's development occurs within a complex system of contexts, activities, social roles, and interpersonal relations that are affected by the wider socio-cultural environment in which the children inhabit. Adjustment to a new situation is seen an ecological transition that: "occurs whenever a person's position in the ecological environment is altered as the 
result of a change in role, setting, or both" (p. 26). This implies that transitions are influenced directly or indirectly by a) the interactions and relationships that occur in an interlocking set of microsystems including home, neighborhood, primary, and secondary school; b) the knowledge, attitudes, predispositions, and skills acquired within these contexts; c) the interrelationships among these microsystems across time; d) educational policies and programs; and e) cultural values, laws, ideologies, and subcultures (Fabian \& Dunlop, 2007). It is clear that that these variables shape the manner in which students experience primary-secondary transition. Yet, because students can be viewed as active constructors of the transition process, their own psychological and biological structures as well as self-concepts play a significant role in the ways they will adapt to the new school environment.

\section{Transition and Identity Reorientation}

As happens with all complex and multifaceted transformation processes, transition to secondary school involves the establishment of a sense of self-identity in the new setting. Commuting between different developmental contexts demands adjustments and brings about changes in identity, relations, and roles. Moreover, transition to secondary school' in many educational systems occurs at the same time as children enter adolescence. During this period students come to negotiate an excess of interpersonal, biological, cognitive, and academic changes in order to form or reform self-concepts and identity. These are related to academic competence, popularity, reputation, physical appearance, behavioral conduct, self-worth, and self-knowledge (Harter, 1999; Lucey \& Reay, 2000; Tonkin \& Watt, 2003).

Redefining and reconstructing self-concepts is associated with looking at available social, cultural, and cognitive resources that help students make sense of new situations, think and behave in new ways, and encounter new teachers and classmates (Zittoun, 2004). The ways the self is reflected through the interactions with significant others, social comparisons, and evaluations of "fitting in" new environments also plays a significant role in the identity reorientation process (Maunder, Gingham, \& Rogers, 2010).

\section{Negative Effects and Resilience}

Research has shown that transition may have a short-term negative impact on students' academic attainment and achievement, social adjustment, and self-concepts (Evangelou et al., 2008; McAlister, 2012). The decline in academic attainment and achievement following transition observed by researchers and educationalists 
has been associated with several factors, which include the change in students' concepts of themselves as learners, an increasing interest to non-academic activities, student motivation, and social relationships (Eccles \& Wigfield, 1993; Lucey \& Reay, 2000; Zeedyk et al., 2003; Langenkamp, 2010). Regarding adjustment, the sufficiency of information about the new school, the existence of student support programs, and the disruption of friendship networks influence students' success or failure to adjust to secondary school (Barone, Aguire-Deandeis, \& Trickett, 1991). Moreover, during transition, changes in self-concepts and sense of self may become overwhelming and may lead to increased tension between stable and emerging self-identities, and consequently may result in a decline in school performance and adjustment during transition (Eccles, Lord, \& Midgley, 1991; Elias, 2002; Walker, 2002).

It seems that most of the students find their way and adjust sufficiently by the end of their first year at secondary school. However, for those who are especially vulnerable there is still a possibility to poorly manage transition and, as a result, present reduced motivation and poor self-concept, social adjustment, and/or disaffection. Vulnerable students during transition are considered those being immature, shy, less confident, or withdrawn; having reduced sense of competence, self-motivation, and autonomy; being influenced by within-child, micro-systemic, or meso-systemic risk factors; having special educational needs and emotional difficulties (McAlister, 2012).

Cultivating resilience through transition programs can be considered essential in order to support them, negotiate effectively, and change by developing and strengthening relevant age competencies. In particular, educational explorations of transition may focus on offering students opportunities to develop problemsolving and self-regulatory skills. They may focus on enhancing flexibility, creativity, and intrinsic motivation, and cultivating responsibility and social competence. Such explorations may provide students with opportunities to increase autonomy and optimism; stabilize self-concepts; and develop self-confidence, self-esteem, and a sense of self-efficacy (Langenkamp, 2010; Niesel \& Griebel, 2005). Moreover, students may be offered opportunities to develop attachment relationships and a sense of purpose and future and increase a sense of mastery. The following section explores the role of art and creativity to foster resilience and presents examples of how visual arts were used to help students negotiate and reframe transition to be understood as a positive time of new discoveries, transformation, and excitement. 


\section{Transition Through Visual Arts and Creativity}

Creativity is an inherent facilitator of resilience as it has been associated with qualities of resilient individuals, such as flexibility, elasticity, divergent thinking, and self-awareness (Metzl \& Morrell, 2008). Effective use of creative approaches with at-risk students has been documented by art therapists, educators, and researchers (Heise, 2014; Jindal-Snape, 2012; Metzl \& Morrell, 2008). In such approaches, art-making is essential as it is a meaning-making process that has the potential to help students process stressful events and make sense of their worlds (Heise, 2013). Art-making can also provide opportunities for students to speak about and share their own experiences, fears, and concerns in order to discover the cause of possible distress and regulate emotions.

Sixth-graders at a public primary school in Athens were engaged in such a creative process as part of an extended "transition to secondary school" educational project that took place between March and June 2014. The classroom teacher conducted visits to the reception secondary school and disseminated information about the new school and new curriculum subjects. As the Head Teacher ${ }^{2}$ of the school and the art teacher, I conducted this artful inquiry, undertaking the role of teacher-researcher. The classroom teacher and I collaborated throughout the inquiry and exchanged views about students' needs, fears, and worries regarding their forthcoming transition.

The first activity involving the 10 boys and 7 girls in the class engaged them in a spontaneous drawing of their way to secondary school. Most of them portrayed this as a path of learning and change. Depictions of bare roads, streets, and crossroads decorated with flowers, or unadorned stairways with stops from Grade 1 to Grade 6, indicated how these students viewed their way to high school. For students, showing themselves moving from one grade to another was a way to visualize their educational journey. However, at the end of these roads or staircases the depiction of high school was not always clear. This indicated an uncertainty about what the new school would be like, worries about stricter teachers, more homework, not being able to make friends, and being around older pupils. These worries were also expressed in the discussion that followed: "My brother says that teachers in high school are too strict, they expel students who misbehave"; "How many hours per day do we have to study? Will I have free time for soccer as I do now?"; "I think that I will have to register to a different high school. Do you know if I can ask for a transfer because I want to be with my classmates?" 


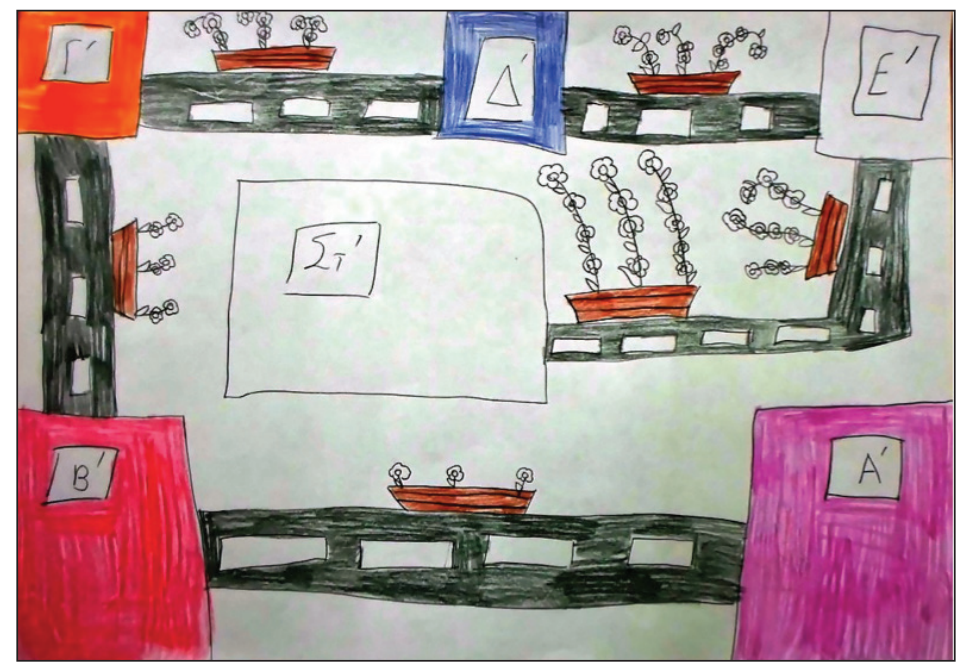

Fig. 1: "My way to high school"- pen and pencil colors by Mathew

Similar concerns and worries were revealed in the two murals the students created working in collaborative groups. These depicted the current and future educational settings. The primary school was portrayed as a beautified, happy place surrounded by trees, flowers and music notes, while the secondary school was represented as an austere building encircled by piles of books with monsters opening the front door or sitting on books. These students probably understood their move to secondary school as a move from a protective, familiar environment into an impersonal and intimidating one. Both art-making activities and the ensuing discussion provided these students with opportunities to express and liberate themselves from anxiety. During the discussion they talked about student responsibilities, possible parent and teachers' expectations, insecurities regarding their own capacities, interests, and future behavior patterns. As one student said:

Starting secondary school means that I must be more responsible and that I should have to study and study and study ... My parents want me to be a good student and go to university so I need to do well in high school.... I think I can manage that as I am a pretty good student here.

These activities appeared to facilitate an understanding of themselves as future secondary school students, which might have helped in regulating negative emotions and led to greater emotional intelligence and resilience (Jindal-Snape, 2012). 


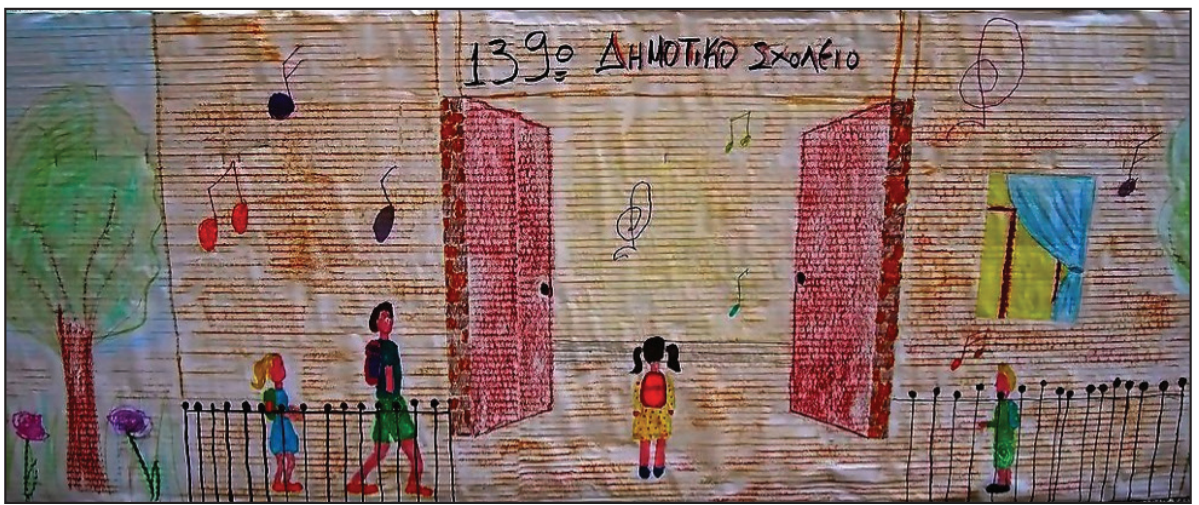

Fig. 2: "Primary school"—felt tip markers and crayons, group work mural

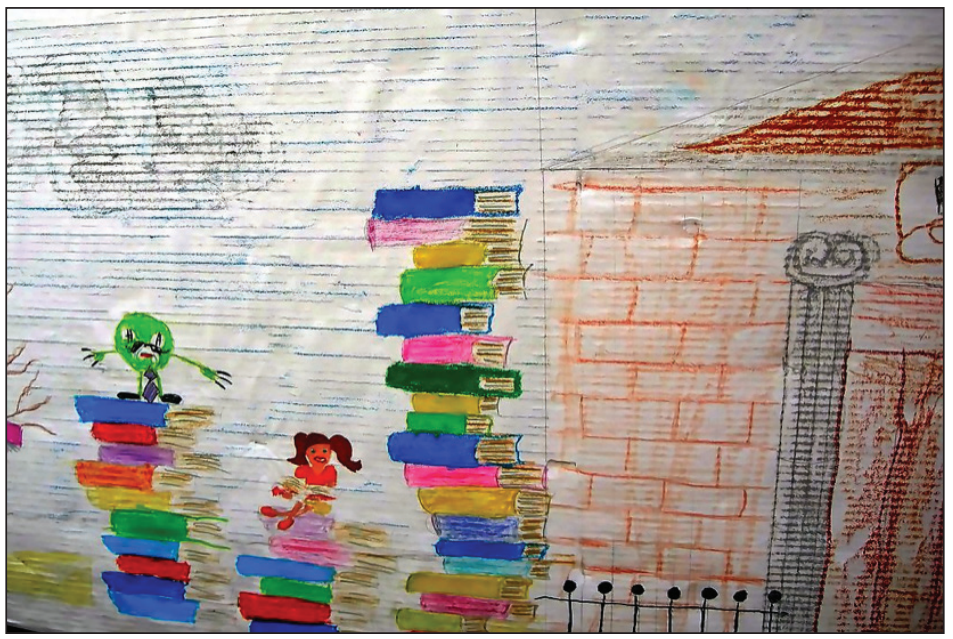

Fig. 3: "High school”-felt tip markers and crayons, detail of group work mural

Since moving to secondary school is connected to simultaneous changes in personal, biological, cognitive, emotional, and environmental levels, the students were asked to explore the concept of change through graffiti, digital photography, and digital video production. The main aim of these activities was for students to learn to respond positively to the changes they would encounter in future. In their graffiti projects most of them approached the concept of "change" with humor and associated it with subjective and age-related changes (i.e., things they used to like or do, changes in appearance, size, and age). For example, a boy illustrated his change in interests, writing that he "used to like ice-creams but now likes girls." It is probable that these students tried to dispel anxiety by using humor, probably because it provides individuals with comfort 
and relief and helps to view perplexing life circumstances in perspective and with optimism. During the collaborative reflection on their graffiti, students appeared to understand "change" as a transformation process that "sometimes makes us feel a little bit confused" and reached at the conclusion that "growing up is a good thing....It is good that I can do things different, by myself and not crying and asking for my mum as I did when I first went to nursery."

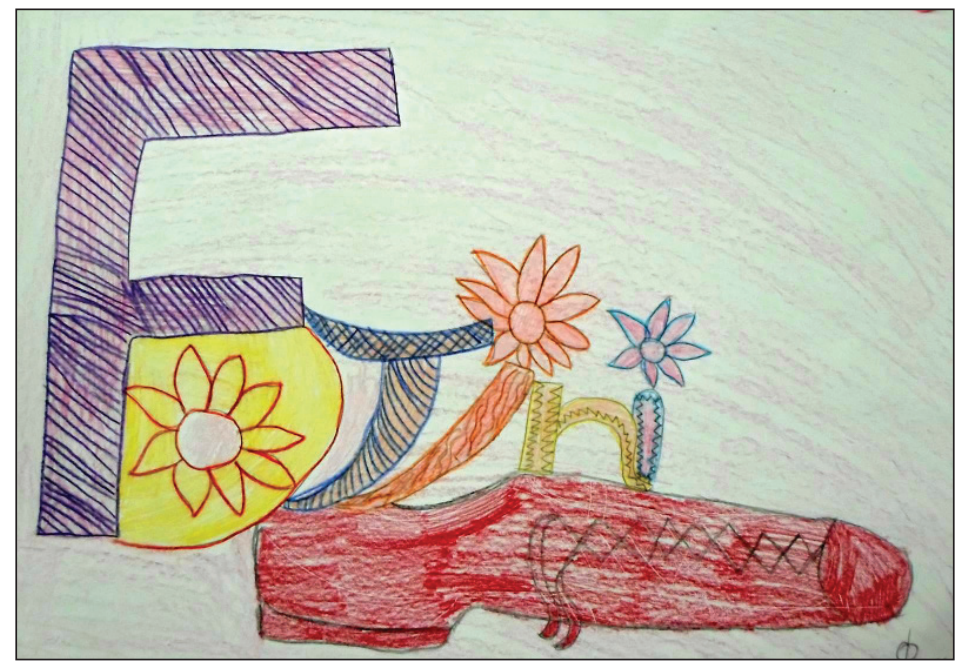

Fig. 4: "Graffiti: change"—-pencil colors and crayons, by Fotini

In their photographic self-portraits these students negotiated potential future changes as they acted out evolving roles and activities associated with age and gender stereotypes regarding physical appearance and behavior. These were related to student responsibilities, personal interests, activities, and attire, such as teenage girls wearing make-up and high-heels, disliking homework, spending time on the Internet, and so forth. By integrating such potential future roles, expectations, and experiences in their art-making, the students had the opportunity to secure a sense of the changing self that might have already begun to emerge. Their verbal accounts about these photographs revealed comparisons between "being" and "becoming." In particular, they revealed concerns and/or subjective appraisals of future bodily and appearance change and self-assessments in relation to others. They also disclosed identifications with cultural and social standards provided by older siblings, peers, mass media, and popular culture resources. 
I'm getting that since day one at high school I have somehow to look a bit different. My sister changed her clothing and hair style to look like a high school student and now she has a boyfriend. That is why I wore lipstick, eyeliner, and the nose earing in these photographs.

Reflecting on their photographic portraits provided students with opportunities to contextualize visions of future selves with some of the social practices associated with adolescence and transition to secondary education. Developing an awareness about the changes in identity that are relevant to transition and about their own predispositions towards particular perceptions, actions, and ways of viewing the secondary school world and themselves, probably gave them the prospect of viewing the whole process of transition with optimism and anticipation.

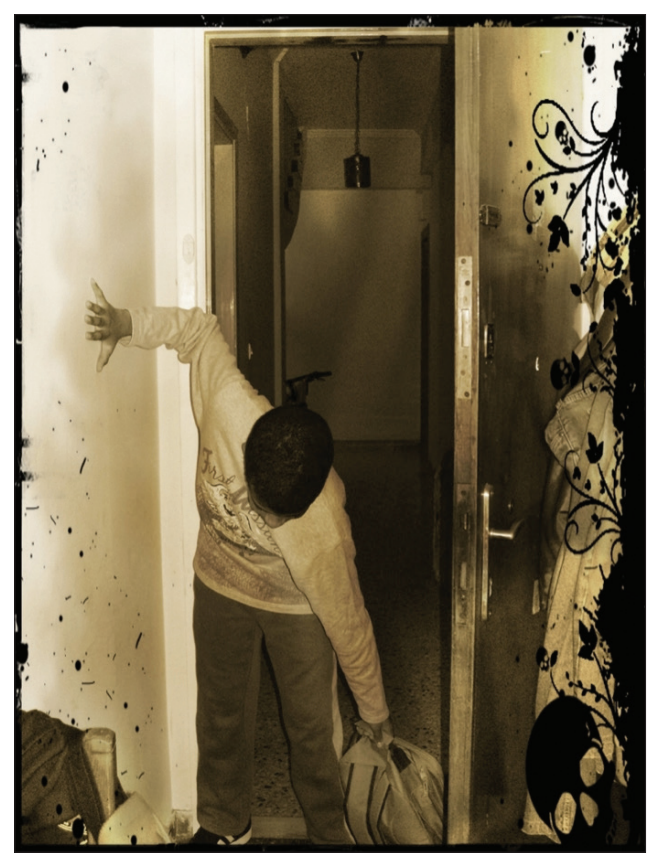

Fig. 5: "It's heavy"—-digital photo by Andrew

Similarly, the students produced a digital video, using these photographic portraits, old photographs of themselves and photographs of artworks they had made during primary school. The concept of the video was to show change over time, so it was named, "I who change." After selecting and processing the photographs with the photo editor software of their choice, the students sequenced them and added music. They particularly enjoyed revisiting and altering photographs, especially those 
transgressive moments of their potential future selves as they added humorous labels and stickers. Throughout the photograph processing and the video production, the students appeared to exercise choice in expressing and presenting themselves and in constructing representations of their own place within the world. To gain greater awareness of how their self-representations were constructed and how images projected particular identities or self-concepts, the students reflected on the choices they made during the creation process and the final product of this activity. Recurring themes in this discussion were: appearance, homework, changing relationships with parents and teachers, and possibilities and/or boundaries of friendship in the new school environment. Student artworks and verbal accounts revealed a considerable amount of projection and planning as they rehearsed new roles and/or situations. For example, one student said: "I didn't use any photographs of myself with any of my old friends from this school. I think I will have to make new ones. It goes with the new school." This awareness, along with the creative experience with and management of digital technologies, offered opportunities to develop problem-solving skills, autonomy, and self-confidence, which are considered resilient traits.

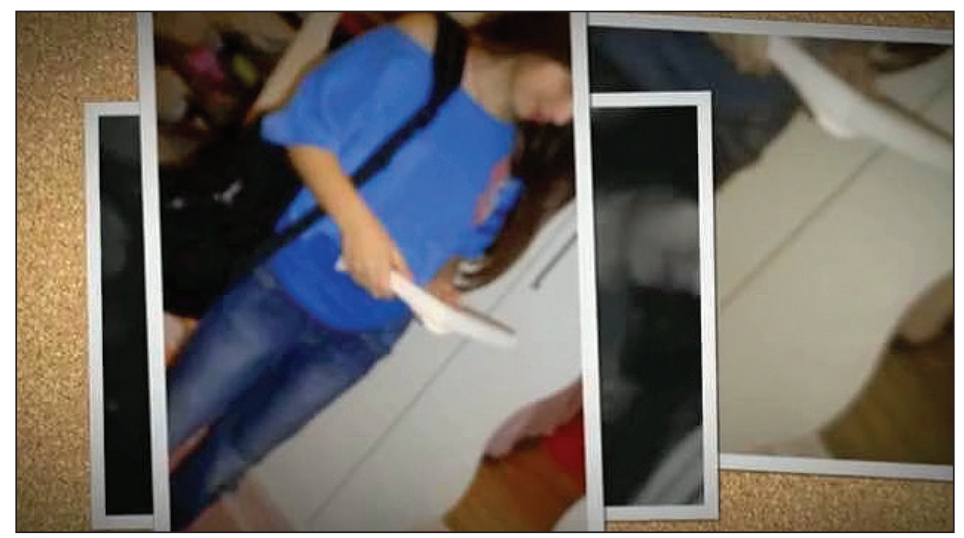

Fig. 6: "Me who change"—snapshot from digital video, by Dora

In these examples, art-making was used to help sixth-grade students to reframe their future transition to secondary school, reduce concerns and anxiety, and transform their thinking about the challenges they might have to deal with in their future lives. Despite the fact that they seemed relieved from tensions or anxiety after lessons, it cannot be assumed that this artful inquiry had the same positive impact on all of them, especially after its completion. By engaging students in problem solving and decision making in the art-making process, critical and creative thinking 
was promoted. However, these students found it demanding to visually represent the elusive concepts of transition, change, and identity. This was counterbalanced through classroom discussion and brainstorming, which proved to be helpful for the majority of them. Obtaining mastery over the art media they used, especially the photo editor and video maker software, required time for experimentation. This was an issue as the time allotted for the art subject was only a 40-minute teaching period per week. To overcome this limitation, students had to experiment at home. The task of obtaining mastery over art media contributed to becoming more flexible as they experimented with them. By encouraging positive emotions, humor, and creativity, these lessons illustrate how fostering resilience can be materialized in art classes since art-making was based on real-life issues that are relevant to students' lives.

\section{Further Practical Considerations}

Other activities, such as visual diaries, book-making, and creative drama, can be also used so that students explore issues relating to transition. Visualizing through art-making or acting out through creative drama real-life scenarios can prepare students for transition to new school as they can rehearse options, actions, emotions, and thoughts (Jindal-Snape, 2012). To celebrate and communicate their achievements during primary school, students could create passports that would include visual and written statements. Or, they can create assemblages of important images and objects to represent their memories of primary school. Also students could explore "the habits or behaviors of resilience" needed in high school (i.e., being self-caring, reliable, compassionate, and courageous through art-making and role-play).

The purpose of these activities is to give students opportunities to express themselves about their forthcoming transition and develop resilient traits. Listening, soothing students' concerns and worries and trying to help them imagine possible solutions to problems, like bullying or isolation, that they may have to deal with through creative arts, is one of the requirements of visual arts programs that explore transitions. For example, through simulated role-play and visual essays, students may explore the changing roles, expectations, and possible future experiences in order to secure a sense of their emerging self. Another requirement is to guide students to use their personal strengths "as a use of ideation for art making" (Heise, 2014, p. 29). For instance, students may negotiate visually, or through creative drama, the interpersonal, biological, cognitive, and academic changes they will encounter in order to acquire an awareness of their personal strengths (i.e., abilities, talents, and skills that contribute to the sense of self). 
In artful inquiries that attend to transition issues by including themes such as identity, self-esteem, friendship, physical appearance, and academic performance, assessment goes beyond the evaluation of outcome of students' work. It also goes beyond the evaluation of use of techniques, materials, and principles, and elements of art and design. Here the assessment's focus should be on students' depth of thinking and independence in exploration of ideas. Responsibility in learning and capacity to collaborate with others should be evaluated as well. It is essential students be given time and opportunities to reflect on the content of their artworks and the processes they used. This can empower them to explore further personal meanings and conceptualizations of these themes and take ownership of their educational experience.

\section{Concluding Thoughts}

This artful inquiry, in conjunction with the "traditional" approaches the classroom teacher used, attempted to provide students with positive transition experiences by engaging them in exploration of possible future changes as a way to increase their sense of competence and confidence. The visual arts can facilitate transition by incorporating strategies to enhance students' self-esteem, resilience, emotional intelligence, and agency (Jindal-Snape, 2012). Providing students with opportunities to visualize their future status as secondary school students as well as their anxieties, concerns, and achievements, has the potential to empower them to manage the change that transition to secondary school presents. Art-making can heal and enhance life as it offers safety and freedom of displaying and expressing desires, opinions, attitudes, concerns, and fears, and relieves tensions. It provides a secure exposure to transition-related issues and, as such, can give students opportunities to challenge them. Moreover, art-making can support and improve transition programs already used by schools as it allows students to make mindful choices and gain some element of control over their environment and the context of learning. 


\section{Notes}

1. Transitions to secondary school occur at different ages in different countries, usually between 11 and 14. In the Greek educational system, students make a transition from primary to secondary school at the age of $11 / 12$.

2. Greek Head Teachers in primary education are expected to perform managerial duties, which mainly involve applying the decisions taken centrally by the Ministry of Education, rather than planning, organizing directing, controlling/evaluating. They also have administrative, pedagogical, and teaching duties (8 to 12 hours per week).

\section{References}

Anderson, L.W., Jacobs, J., Schramm, S., \& Splittgerber, F. (2000). School transitions: Beginning of the end or a new beginning? International Journal of Education, 33, 325-339.

Barone, C., Aguire-Deandeis, A. I., \& Trickett, E.J. (1991). Mean-ends problem solving skills, life stress, and social support as mediators of adjustment in the normative transition to high school. American Journal of Community Psychology, 19(2), 207-225.

Bronfenbrenner, U. (1979). The ecology of human development: Experiments by nature and design. Massachusetts, USA: Harvard University Press.

Eccles, J. S., \& Wigfield, A. (1993). Negative effects of traditional middle schools on students' motivation. Elementary School Journal, 93(5), 553-574.

Eccles, J.S., Lord, S., \& Midgley, C. (1991). What are we doing to early adolescents? The impact of educational contexts on early adolescents. American Journal of Education, 99(4), 521-542.

Elias, M. J. (2002). Transitioning to middle school. The Education Digest, 67(8), 41-43.
Evangelou, M., Taggart, B, Sylva, K., Melhuish, E., Sammons, P., \& Siraj-Blatchford, I. (2008). Effective pre-school, primary and secondary education 3-14 Project: What makes a successful transition from primary to secondary school? Research Report DCSF: Institute of Education London.

Fabian, H., \& Dunlop, A. (2005). The importance of play in the transition to school. In J.R. Moyles (Ed.), The excellence of play (2nd edition). Berkshire: Open University Press/ McGraw-Hill.

Fabian, H., \& Dunlop, A. (2007). Outcomes of good practice in transition processes for children entering primary school. Working Paper 42. The Hague, Netherlands: Bernard Van Leer Foundation.

Gorgorió, N., Planas, N., \& Vilella, X. (2002). Immigrant children learning mathematics in mainstream schools. In G. de Abreu, A. Bishop, \& N.C. Presmeg (Eds.), Transitions between contexts of mathematical practice (pp. 23-52). The Netherlands: Kluwer Academic Publishers.

Hanewald, R. (2013). Transition between primary and secondary school: Why it is important and how it can be supported. Australian Journal of Teacher Education, 38(1), 62-74. 
Harter, S. (1999). The construction of the self: A developmental perspective. New York: Guilford.

Heise, D. (2013). Fostering resilience through art. In K. Tavin \& C. Ballengee-Morris (Eds.), Stand(ing) up, for a change: Voices of arts educators (pp. 112-120). Reston, VA. National Art Education Association.

Heise, D. (2014). Steeling and resilience. Art Education, 67(3), 26-30.

Jindal-Snape, D. (2012). Portraying children's voices through creative approaches to enhance their transition experience and improve the transition practice. LEARNing Landscapes, 6(1), 223-240.

Langenkamp, A.G. (2010). Academic vulnerability and resilience during the transition to high school: The role of social relationships and district context. Sociology of Education, 83(1), 1-19.

Lucey, H., \& Reay, D. (2000). Identities in transition: Anxiety and excitement in the move to secondary school. Oxford Review of Education, 26(2), 191-205.

Maunder, R., Gingham, J., \& Rogers, J. (2010). Transition in higher education: Exploring the experience of first and second year psychology undergraduate students. Psychology of Education Review, 34(1), 50-54.

McAlister, J. E. (2012). A realistic evaluation of transition programmes in two secondary schools in a small multi-cultural city in the midlands: How are the needs of vulnerable young people met during the transition from primary to secondary school? Unpublished $\mathrm{PhD}$ thesis, University of Birmingham.
Metzl, E.S., \& Morrell, M. A. (2008). The role of creativity in models of resilience: Theoretical exploration and practical applications. Journal of Creativity in Mental Health, 3(3), 303-318.

Niesel, R., \& Griebel, W. (2005). Transition competence and resiliency in educational institutions. International Journal of Transitions in Childhood, 1, 4-11.

Tonkin, S. E., \& Watt, H. M. (2003). Self-concept over the transition from primary to secondary school: A case study on a program for girls. Issues in Educational Research, 13(2), 27-54.

Walker, M. (2002). From junior high to middle school: Orchestrating the Punahou transition. Independent School, 61(4), 10-15.

Zeedyk, M.S., Gallacher, J., Henderson, M., Hope, G., Husband, B., \& Lindsay, K. (2003). Negotiating the transition from primary to secondary school. Perceptions of pupils, parents and teachers. School Psychology International, 24(1), 67-69.

Zittoun, T. (2004). Symbolic competencies for developmental transitions: The case of the choice of first names. Culture \& Psychology, 10(2), 131-161. 


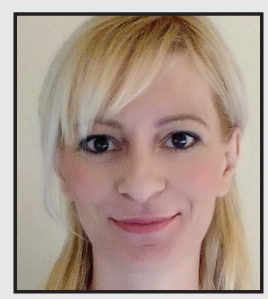

Martha Christopoulou, PhD, is Head Teacher at a Primary School in Athens, Greece. Her research interests are predominantly in art and visual culture education. At present she is researching issues relevant to primary students' lives such as transition to secondary school and the impact of the Greek financial crisis on their lives. She is also researching ways of developing art/visual culture curricula that promote resilience. She has published several articles in international and Greek educational journals. 